\title{
Measurement of cardiac reserve in cardiogenic shock: implications for prognosis and
}

\section{management}

\author{
Lip-Bun Tan, William A Littler
}

In cardiogenic shock the basal resting performance of the heart may be appreciably depressed, but if there is sufficient reserve it is likely that the heart will recover and function adequately again. To evaluate cardiac reserve fully the heart has to be stimulated to enhance its performance by increasing the heart rate, preload, and contractility from basal values.

In cardiogenic shock, preload reserve is either fully used (with considerably increased left ventricular filling pressure) or inconsequential (because of the flattened Starling curve). However, in a few patients there may be relative hypovolaemia. ${ }^{6}$ Careful fluid challenge would show the amount of reserve present; those with limited preload reserve had a poorer prognosis. ${ }^{78}$ Inotropic and chronotropic stimulation with dobutamine was used to assess cardiac pumping reserve in a group of patients with severe heart failure; the information was of prognostic value. ${ }^{9}$ The aim of the present study was to investigate whether similar information about cardiac reserve can be obtained by dobutamine stimulation in patients with cardiogenic shock, after optimalising the preload. A prospective study was conducted to test the hypothesis that in cardiogenic shock the magnitude of cardiac pumping reserve is predictive of outcome.

\section{Patients and methods}

\section{PATIENTS}

We studied patients admitted to the coronary care unit in East Birmingham Hospital between September 1984 and June 1986 with clinical manifestations of cardiogenic shock. All patients who fulfilled the selection criteria described below were included. The syndrome of shock was diagnosed according to Cohn's criteria. ${ }^{10}$ All the patients had at least two of the clinical features of shock: oliguria with urine output $<20 \mathrm{ml} /$ hour, cool moist skin, auscultatory systolic blood pressure $<90$ $\mathrm{mm} \mathrm{Hg}$, obtunded mental state, metabolic acidosis.

We excluded patients with all other causes of shock including those attributable to arrhythmias that were not controlled and to drugs (for example opiates). We excluded relative hypovolaemia by showing that fluid challenge did not lead to any improvement in cardiac performance in patients in whom right ventricular infarction was suspected or pulmonary wedge pressure was $<18 \mathrm{~mm} \mathrm{Hg}$. Patients with complete heart block were paced before entry into the study. Since one of the
The reserve of the cardiac pump is a major determinant of survival in patients with cardiogenic shock. We examined whether cardiac reserve correlated with prognosis. 
aims of this study was to determine objectively which patient should be treated with ventricular assist devices or emergency cardiac surgery, only patients treated medically were included-that is those who were not suitable for surgery or those who refused surgery and insertion of intra-aortic counterpulsation balloon pumps. None of the patients had angina pectoris, papillary muscle dysfunction or rupture, ventricular septal defect or ventricular rupture, and none was treated with thrombolytic agents. Twenty eight patients (seven women, 21 men; mean age 59 (range 3673)) fulfilled the above criteria. In 24 patients cardiogenic shock developed after acute myocardial infarction (established by appropriate history and clinical observations, in association with documented electrocardiographic evidence of infarction and serial changes in serum enzyme concentrations) and in four shock developed after exacerbation of chronic cardiac failure caused by ischaemic heart disease. These four patients were included because we wanted to include all patients with true cardiogenic shock irrespective of cause, who fulfilled the selection criteria.

\section{PROTOCOL}

As part of the standard management of patients with cardiogenic shock, thermodilution SwanGanz catheters and arterial cannulas were inserted, and these provided readings of right atrial (RAP), mean systemic arterial (MBP), pulmonary arterial (PAP) and wedge (PAWP) pressures, and cardiac output $(\mathrm{CO}$, measured in triplicate). The heart rate (HR) was obtained from the electrocardiogram. The left ventricular ejection fraction (LVEF) at basal resting state was estimated by cross sectional echocardiography.

The following equations were used to calculate the haemodynamic variables (all pressures were measured in $\mathrm{mm} \mathrm{Hg}$ and cardiac output $(\mathrm{CO})$ in $1 . \mathrm{min}^{-1}$ : cardiac index $(\mathrm{CI}=$ $\mathrm{CO} /$ body surface area, $\left.1 . \mathrm{min}^{-1} \cdot \mathrm{m}^{-2}\right)$; stroke volume index $\left(\mathrm{SVI}=\mathrm{CI} / \mathrm{HR}, \mathrm{ml} . \mathrm{m}^{-2}\right)$; left ventricular stroke work index (LVSWI = $($ MBP-PAWP $) \times$ SVI $\times 0.133\left(\mathrm{~J}^{-\mathrm{m}^{-2}}\right), \mathrm{con}-$ version to g.m.m ${ }^{-2}$ by multiplication by $102.04)$; systemic vascular resistance $(\mathrm{SVR}=$ $\left(\mathrm{MBP}\right.$ - mean RAP)/CO $\times$ 8, kPa.s. $\mathrm{l}^{-1}$, conversion to dyn.s. $\mathrm{cm}^{-5}$ by multiplication by 10); pulmonary vascular resistance (PVR = (mean PA pressure - mean PAW pressure) $\times$ $\mathrm{CO} \times 8$, kPa.s. $1^{-1}$; ; cardiac power output $(\mathrm{CPO}=(\mathrm{MBP}-\mathrm{RAP}) \times \mathrm{CO} \times 2.2167 \times$ $\left.10^{-3} \mathrm{~W}\right)$.

Dobutamine infusion was indicated in all patients on clinical grounds. A dose titration of dobutamine was used to assess the haemodynamic response (doses from $2.5 \mu \mathrm{g} / \mathrm{kg} / \mathrm{min}$ increased by 2.5 or $5.0 \mu \mathrm{g} / \mathrm{kg} / \mathrm{min}$ to a maximum of $15-40 \mu \mathrm{g} / \mathrm{kg} / \mathrm{min}$ every $5-10 \mathrm{~min}$ ). Maximum stimulation was assumed when there was no further rise in cardiac power output.

The patients were followed up for at least a year. Those who survived for more than a year were termed "survivors" and those who did not the "non-survivors". We selected this follow up period because we knew that the final events leading to death are unpredictable, and that the interval between shock and death may be short when the terminal event is arrhythmia or longer when death is due to cardiac cachexia or renal failure. During the follow up, heart failure was treated conventionally with diuretics, digoxin, and vasodilators. To test the hypothesis that indicators of cardiac pumping reserve were predictive of outcome we compared haemodynamic function at basal resting state and during maximal dobutamine stimulation in survivors with that in those who died.

Table 1 Clinical and baseline haemodynamic data in individual patients

\begin{tabular}{|c|c|c|c|c|c|c|c|c|c|c|c|c|c|c|}
\hline $\begin{array}{l}\text { Case } \\
\text { No }\end{array}$ & $\begin{array}{l}\text { Age } \\
y r\end{array}$ & Sex & $\begin{array}{l}B S A \\
\left(m^{2}\right)\end{array}$ & $\begin{array}{l}\text { Aetiology of } \\
\text { cardiogenic } \\
\text { shock }\end{array}$ & Survived/died & $\begin{array}{l}\text { Time to } \\
\text { death }\end{array}$ & $\begin{array}{l}\text { LVEF } \\
(\%)\end{array}$ & $H R$ & $R A P$ & $P A W P$ & $C I$ & $S V I$ & $L V S W I$ & $C P O$ \\
\hline $\begin{array}{r}1 \\
2 \\
3 \\
4 \\
5 \\
6 \\
7 \\
8 \\
9 \\
10 \\
11 \\
12 \\
13 \\
14 \\
15 \\
16 \\
17 \\
18 \\
19 \\
20 \\
21 \\
22 \\
23 \\
24 \\
25 \\
26 \\
27 \\
28\end{array}$ & $\begin{array}{l}62 \\
56 \\
72 \\
48 \\
64 \\
64 \\
52 \\
63 \\
46 \\
64 \\
59 \\
64 \\
64 \\
62 \\
63 \\
69 \\
54 \\
51 \\
55 \\
67 \\
55 \\
40 \\
73 \\
51 \\
68 \\
36 \\
68 \\
63\end{array}$ & $\begin{array}{l}M \\
M \\
F \\
M \\
M \\
F \\
M \\
M \\
M \\
F \\
M \\
F \\
M \\
F \\
M \\
F \\
M \\
M \\
M \\
F \\
M \\
M \\
M \\
M \\
M \\
M \\
M \\
M\end{array}$ & $\begin{array}{l}1.50 \\
1.70 \\
1.60 \\
1.72 \\
1.84 \\
1.50 \\
1.71 \\
1.79 \\
1.82 \\
1.62 \\
1.92 \\
1.60 \\
1.82 \\
1.76 \\
2.05 \\
1.60 \\
1.72 \\
2.30 \\
1.90 \\
1.50 \\
1.86 \\
1.86 \\
1.81 \\
1.88 \\
1.78 \\
1.94 \\
1.78 \\
1.72\end{array}$ & $\begin{array}{l}\text { IHD, E-CCF } \\
\text { AMI, LVF } \\
\text { AMI, BVF } \\
\text { AMI, LVF } \\
\text { AMI, CCF } \\
\text { AMI, BVF } \\
\text { AMI, LVF } \\
\text { AMI, LVF } \\
\text { AMI, CCF } \\
\text { AMI, LVF, CHB } \\
\text { IHD, E-CCF } \\
\text { AMI, BVF } \\
\text { AMI, LVF } \\
\text { AMI, LVF } \\
\text { AMI, LVF } \\
\text { AMI, LVF, CHB } \\
\text { AMI, CCF } \\
\text { AMI, LVF } \\
\text { AMI, RVMI, LVF } \\
\text { AMI, LVF } \\
\text { AMI, LVF } \\
\text { AMI, RVMI, LVF } \\
\text { AMI, LVF } \\
\text { IHD, E-CCF } \\
\text { IHD, E-CCF } \\
\text { AMI, LVF } \\
\text { AMI, LVF } \\
\text { AMI, LVF }\end{array}$ & 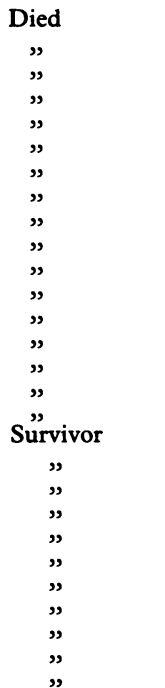 & $\begin{array}{l}12 \text { wks } \\
2 \text { days } \\
2 \text { days } \\
1 \text { day } \\
9 \text { days } \\
1 \text { day } \\
6 \text { wks } \\
3 \text { days } \\
4 \text { days } \\
2 \text { days } \\
17 \text { days } \\
1 \text { day } \\
2 \text { days } \\
1 \text { day } \\
7 \text { days } \\
2 \text { days } \\
8 \text { days } \\
>1 \mathrm{yr} \\
>1 \mathrm{yr} \\
>1 \mathrm{yr} \\
>1 \mathrm{yr} \\
>1 \mathrm{yr} \\
>1 \mathrm{yr} \\
>1 \mathrm{yr} \\
>1 \mathrm{yr} \\
>1 \mathrm{yr} \\
>1 \mathrm{yr} \\
>1 \mathrm{yr}\end{array}$ & $\begin{array}{r}12 \\
35 \\
20 \\
27 \\
26 \\
15 \\
21 \\
32 \\
20 \\
7 \\
15 \\
35 \\
16 \\
17 \\
30 \\
25 \\
27 \\
16 \\
48 \\
22 \\
17 \\
8 \\
27 \\
15 \\
21\end{array}$ & $\begin{array}{r}86 \\
71 \\
140 \\
115 \\
132 \\
93 \\
101 \\
112 \\
117 \\
110 \\
80 \\
63 \\
100 \\
136 \\
95 \\
90 \\
109 \\
109 \\
97 \\
75 \\
98 \\
80 \\
80 \\
92 \\
55 \\
91 \\
97 \\
77\end{array}$ & $\begin{array}{r}17 \\
18 \\
30 \\
8 \\
20 \\
26 \\
9 \\
18 \\
16 \\
13 \\
22 \\
20 \\
15 \\
14 \\
18 \\
14 \\
4 \\
14 \\
20 \\
5 \\
7 \\
21 \\
8 \\
18 \\
18 \\
12 \\
17 \\
10\end{array}$ & $\begin{array}{l}23 \\
19 \\
30 \\
29 \\
32 \\
31 \\
19 \\
32 \\
28 \\
16 \\
34 \\
29 \\
30 \\
25 \\
20 \\
24 \\
35 \\
19 \\
28 \\
16 \\
20 \\
19 \\
17 \\
29 \\
26 \\
22 \\
38 \\
23\end{array}$ & $\begin{array}{l}2 \cdot 4 \\
1.2 \\
1.4 \\
2 \cdot 2 \\
1.8 \\
0.9 \\
2.1 \\
1.4 \\
2.4 \\
1 \cdot 1 \\
1 \cdot 1 \\
1.3 \\
1.5 \\
1.8 \\
1.8 \\
1.3 \\
2.3 \\
1.5 \\
2.6 \\
2.5 \\
2.4 \\
2.6 \\
2.2 \\
1.6 \\
2.0 \\
1.3 \\
3.3 \\
2.0\end{array}$ & 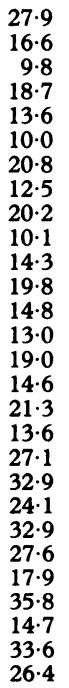 &  & $\begin{array}{l}0.37 \\
0.13 \\
0.15 \\
0.57 \\
0.34 \\
0.15 \\
0.55 \\
0.33 \\
0.56 \\
0.20 \\
0.22 \\
0.13 \\
0.21 \\
0.39 \\
0.49 \\
0.24 \\
0.69 \\
0.47 \\
0.58 \\
0.57 \\
0.64 \\
0.47 \\
0.55 \\
0.42 \\
0.48 \\
0.36 \\
0.75 \\
0.47\end{array}$ \\
\hline
\end{tabular}

AMI, acute myocardial infarction; BSA, body surface area; BVF, biventricular failure; CCF, chronic cardiac failure; CHB, complete heart block; E-CCF, exacerbation of CCF; IHD, ischaemic heart disease; LVF, left ventricular failure; RVMI, right ventricular myocardial infarction. 
Figure 1 Resting

haemodynamic data of

survivors $(S)$ v non-

survivors $(N-S):(A)$

cardiac index, $(B)$ left

ventricular stroke work index, (C) left ventricula ejection fraction, (D) mean pulmonary artery wedge pressure (PAWP) Mean values and $99 \%$ confidence intervals are shown.
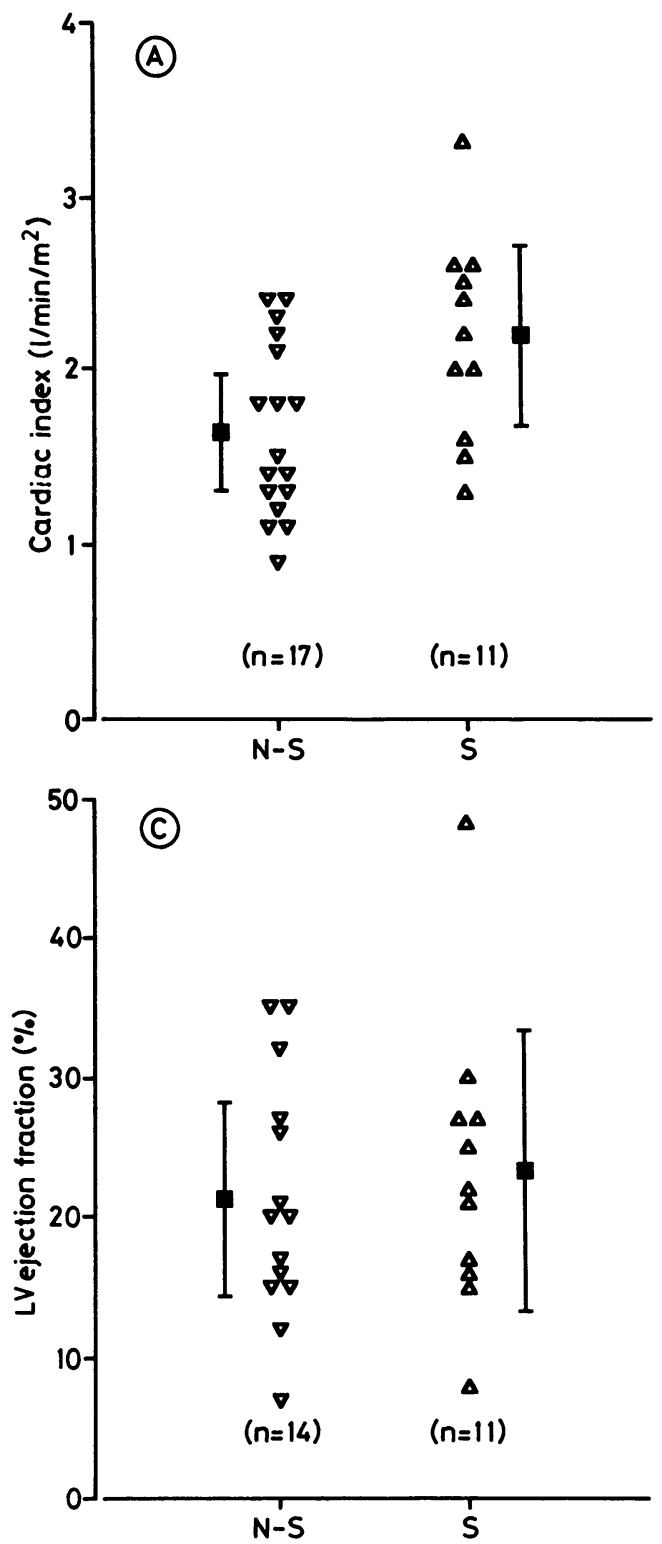

STATISTICAL ANALYSIS

We used Bonferroni's analysis of variance to compare the differences between survivors and non-survivors and a paired $t$ test to assess the significance of changes brought about by dobutamine. Differences were regarded as significant at $p<0.01$. Results were expressed as means (SEM).

\section{Results}

MORTALITY

Table 1 shows the clinical data and survival of the patients. These 28 cardiogenic shock patients were clinically indistinguishable and were all considered to have a grave prognosis before the haemodynamic study. Seventeen died during follow up. All but two of these patients died of progressive cardiac failure while in hospital, within 3 weeks of the diagnosis of shock. The average time between diagnosis of shock and death in hospital was 4 days. One of the two exceptions died at home after 10 weeks of progressive heart failure (New York Heart Association class IV throughout). The other was discharged in New York Heart Association class III but was readmitted 4
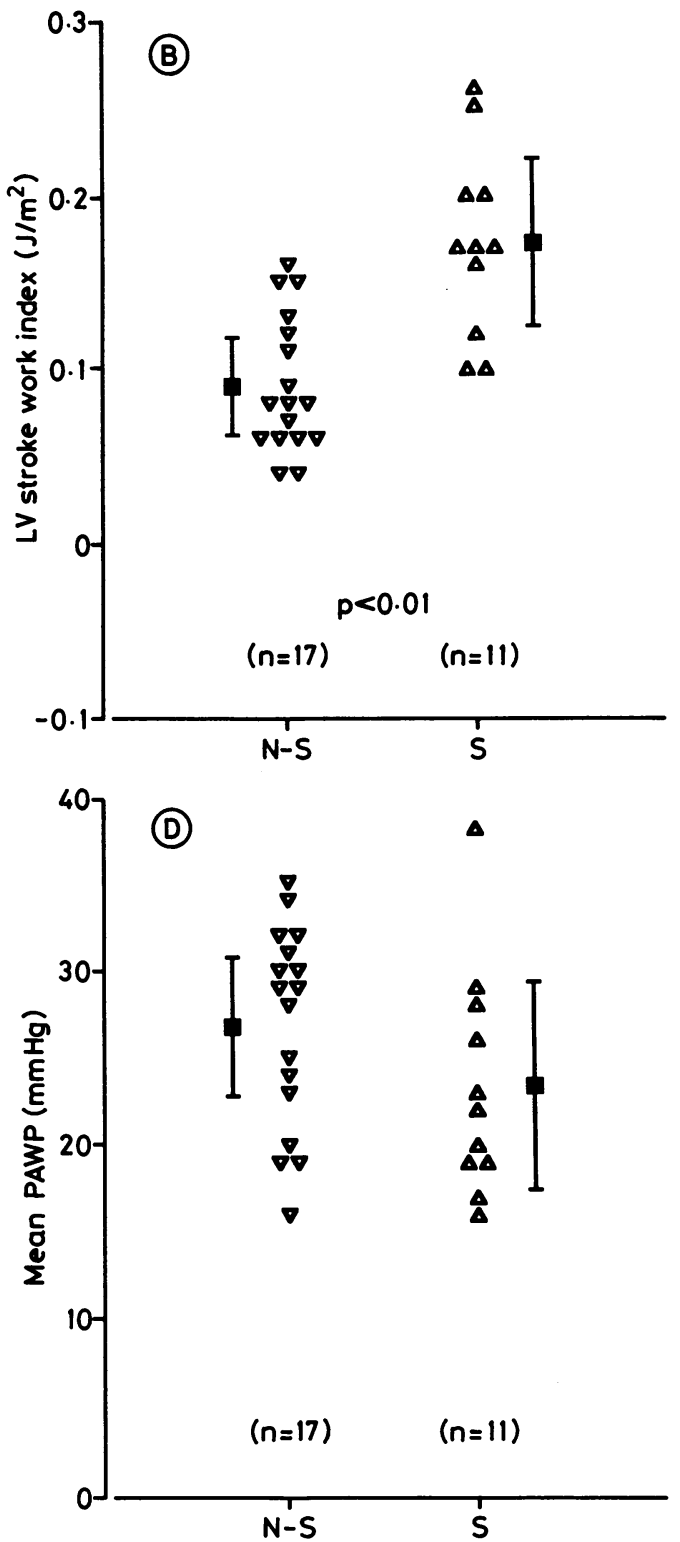

weeks later and died of intractable ventricular tachycardia. The eleven survivors lived more than a year and were in New York Heart Association class III or better when reviewed at six months and one year after discharge from hospital.

\section{BASAL HAEMODYNAMIC DATA}

Table 1 and fig 1 show the baseline haemodynamic data of individual patients. The mean (SEM) left ventricular ejection fraction at basal resting state for the entire group was 22.2 $(1.9) \%$. Table 2 shows the mean basal haemodynamic values for all the patients. The data suggested that ventricular performance was more depressed in those who died, though only the left ventricular stroke work index was significantly different in the two groups. Figure 1A identifies a clear subset of four patients who died, defined by resting cardiac index of $<1.31 . \mathrm{min}^{-1} \cdot \mathrm{m}^{-2}$. Although patients with a resting cardiac index of between 1.3 and $2 \cdot 41 . \mathrm{min}^{-1} \cdot \mathrm{min}^{-2}$ were also at high risk several within this range survived. Similarly, all (11) patients with basal left ventricular stroke work index $<0.1 \mathrm{~J} . \mathrm{m}^{-2}$ died (fig 1B), whereas all those with stroke work index $>0.16 \mathrm{~J} . \mathrm{m}^{-2}$ 
Table 2 Haemodynamic response (mean (SEM)) to peak dobutamine infusion

\begin{tabular}{|c|c|c|c|c|c|c|c|}
\hline \multirow{3}{*}{ HR: } & \multirow{3}{*}{$\begin{array}{l}\text { Basal } \\
\text { Peak }\end{array}$} & \multicolumn{2}{|c|}{ All patients } & \multicolumn{2}{|c|}{ Survivors } & \multicolumn{2}{|c|}{ Non-survivors } \\
\hline & & 96.5 & $(3 \cdot 8)$ & $86 \cdot 5$ & $(4 \cdot 3)$ & 102.9 & $(5 \cdot 1)$ \\
\hline & & 111.4 & $(3 \cdot 6)^{\star \star}$ & $106 \cdot 3$ & $(4 \cdot 7)^{\star \star}$ & $114 \cdot 7$ & $(4 \cdot 9)^{\star}$ \\
\hline RAP: & Basal & 15.4 & $(1 \cdot 1)$ & $13 \cdot 6$ & $(1 \cdot 6)$ & $16 \cdot 6$ & $(1.5)$ \\
\hline & Peak & $12 \cdot 8$ & $(1 \cdot 2)^{\star}$ & 11.5 & $(2.0)$ & 13.6 & $(1 \cdot 4)^{\star}$ \\
\hline MPAP: & $\begin{array}{l}\text { Basal } \\
\text { Peak }\end{array}$ & $\begin{array}{l}36 \cdot 1 \\
35.9\end{array}$ & $(1.7)$ & $\begin{array}{l}35.9 \\
33.8\end{array}$ & (2.7) & $36 \cdot 2$ & $(2 \cdot 1)$ \\
\hline PAWP: & Basal & $\begin{array}{l}35.9 \\
25.5\end{array}$ & $\begin{array}{l}(1 \cdot 9) \\
(1 \cdot 1)\end{array}$ & $\begin{array}{l}33 \cdot 8 \\
23 \cdot 4\end{array}$ & $\begin{array}{l}(3.3) \\
(1.9)\end{array}$ & $\begin{array}{l}37 \cdot 2 \\
26 \cdot 8\end{array}$ & $\begin{array}{l}(2 \cdot 3) \\
(1 \cdot 4)\end{array}$ \\
\hline & Peak & 23.7 & $(1.5)$ & $18 \cdot 8$ & $(2 \cdot 2)$ & 26.8 & $(1.7)$ \\
\hline MBP: & Basal & 69.8 & $(1 \cdot 7)$ & 73.5 & $(1 \cdot 3)$ & $67 \cdot 4$ & $(2.5)$ \\
\hline & Peak & $80 \cdot 1$ & $(2 \cdot 6)^{\star \star}$ & $88 \cdot 3$ & $(3 \cdot 2)^{\star}$ & 74.8 & $(3 \cdot 1)^{\star}$ \\
\hline CI: & Basal & 1.9 & $(0 \cdot 1)$ & $2 \cdot 2$ & $(0 \cdot 2)$ & 1.6 & $(0 \cdot 1)$ \\
\hline SVI: & $\begin{array}{l}\text { Peak } \\
\text { Basal }\end{array}$ & $\begin{array}{r}3.0 \\
20 \cdot 1\end{array}$ & $\begin{array}{l}(0 \cdot 2)^{\star \star} \\
(1 \cdot 4)\end{array}$ & $\begin{array}{r}4 \cdot 0 \\
26 \cdot 1\end{array}$ & $\begin{array}{l}(0 \cdot 1)^{\star \star \ddagger} \\
(2 \cdot 2)\end{array}$ & $\begin{array}{r}2 \cdot 4 \\
16 \cdot 3\end{array}$ & $\begin{array}{l}(0 \cdot 1)^{\star \star} \\
(1 \cdot 2)\end{array}$ \\
\hline & Peak & $28 \cdot 3$ & $(2 \cdot 0)^{\star \star}$ & $38 \cdot 7$ & $(2.0)^{\star \star \ddagger}$ & 21.6 & $(1.5)^{\star \star}$ \\
\hline LVSWI: & Basal & $12 \cdot 2$ & $(1 \cdot 1)$ & $17 \cdot 2$ & $(1.5)+{ }^{+}$ & 9.0 & $(1 \cdot 0)$ \\
\hline & Peak & $22 \cdot 2$ & $(2 \cdot 2)^{\star \star}$ & $35 \cdot 2$ & $(1 \cdot 3)^{\star \star \ddagger}$ & 13.7 & $(1 \cdot 2)^{\star \star}$ \\
\hline CPO: & Basal & 0.41 & $(0.03)$ & 0.52 & $(0.03)$ & 0.34 & $(0.04)$ \\
\hline PYR. & Peak & $\begin{array}{c}0.84 \\
26.5\end{array}$ & $(0.07)^{\star \star}$ & $\begin{array}{c}1.25 \\
26 \cdot 2\end{array}$ & $(0.04)^{\star \star} \ddagger$ & $\begin{array}{r}0.57 \\
26.6\end{array}$ & $(0.05)^{\star \star}$ \\
\hline PVR: & $\begin{array}{l}\text { Basal } \\
\text { Peak }\end{array}$ & $\begin{array}{l}26 \cdot 5 \\
18 \cdot 5\end{array}$ & $\begin{array}{l}(2 \cdot 6) \\
(1 \cdot 7)^{\star \star}\end{array}$ & $\begin{array}{l}26 \cdot 2 \\
16 \cdot 1\end{array}$ & $\begin{array}{l}(3 \cdot 4) \\
(2 \cdot 0)^{\star \star}\end{array}$ & $\begin{array}{l}26 \cdot 6 \\
20.0\end{array}$ & $\begin{array}{l}(3.6) \\
(2.4)\end{array}$ \\
\hline SVR: & Basal & 141.4 & $(8 \cdot 2)$ & $127 \cdot 4$ & $(10 \cdot 6)$ & 150.5 & $(11.0)$ \\
\hline & Peak & $109 \cdot 1$ & $(7 \cdot 1)^{\star \star}$ & $85 \cdot 1$ & $(6 \cdot 2)^{\star}$ & $124 \cdot 6$ & $(9 \cdot 1)$ \\
\hline
\end{tabular}

${ }^{\star} \mathrm{p}<0.01$ and ${ }^{*} \mathrm{p}<0.001$, basal $v$ peak.

tp $<0.01$ and $\neq \mathrm{p}<0.001$, survivors $v$ non-survivors.

CI, cardiac index $\left(1 . \mathrm{min}^{-1} \cdot \mathrm{m}^{-2}\right)$; CPO, cardiac power output (W); HR, heart rate (beats/min); LVSWI, left ventricular stroke work index $\left(10^{-2} \mathrm{~J} \cdot \mathrm{m}^{-2}\right) ; \mathrm{MBP}$, mean systemic arterial pressure (mm Hg); MPAP, mean pulmonary artery arterial pressure $(\mathrm{mm} \mathrm{Hg}) ;$ PAWP, pulmonary arter wedge pressure (mm Hg); PVR, pulmonary vascular resistance ( $\mathrm{mPa.s.} .^{-1}$ ); RAP, right atrial pressure (mm Hg); SVI, stroke volume index $\left(\mathrm{ml}^{\left.-\mathrm{m}^{-2}\right)}\right.$; SVR, systemic vascular resistance $\left(\mathrm{kPa} . \mathrm{I}^{-1}\right)$.
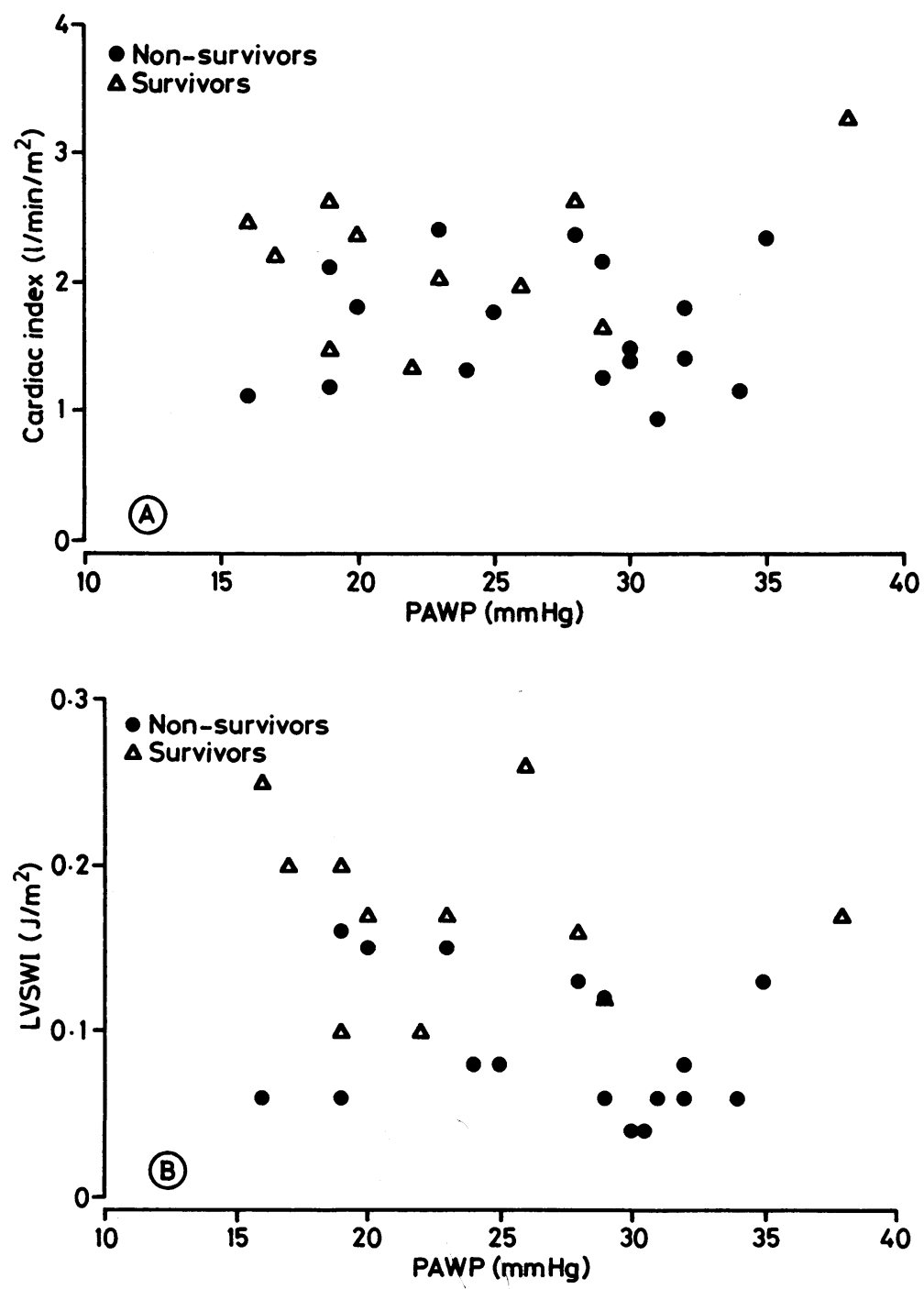

Figure 2 Relation between $(A)$ cardiac index and mean pulmonary artery wedge pressure $(P A W P)$ and $(B)$ left ventricular stroke work index (LVSWI) and pulmonary artery wedge pressure at basal resting states. survived; between these two values the results overlapped. In figs $1 \mathrm{C}$ and $\mathrm{D}$ the overlap of the values for pulmonary artery wedge pressure and left ventricular ejection fraction were even more conspicuous and values of the two groups were not significantly different.

A basal left ventricular filling pressure $>15$ $\mathrm{mm} \mathrm{Hg}$ and a cardiac index $<2 \cdot 31 . \mathrm{min}^{-1} \cdot \mathrm{m}^{-2}$ were defined by Ratshin and colleagues in 1972 as criteria identifying the subset who will all die, ${ }^{7}$ but several survivors in our patient population had values in this range. Similarly, the relation between left ventricular stroke work index and filling pressure at rest, used to identify high risk cases in Vincent et al's study, ${ }^{11}$ did not clearly separate the survivors from the non-survivors (fig 2).

\section{RESPONSE TO INOTROPIC STIMULATION}

After optimalisation of the preload (by fluid challenge until there was no further rise in cardiac output or cardiac power output), cardiac reserve was assessed by noting the response to inotropic stimulation by dobutamine infusion. Figures $3 A$ and $B$ show the cardiac index and power output of four representative patients from the survivor and non-survivor subsets. Both the cardiac index and power output increased with dobutamine dosages. At the peak dosages further increases
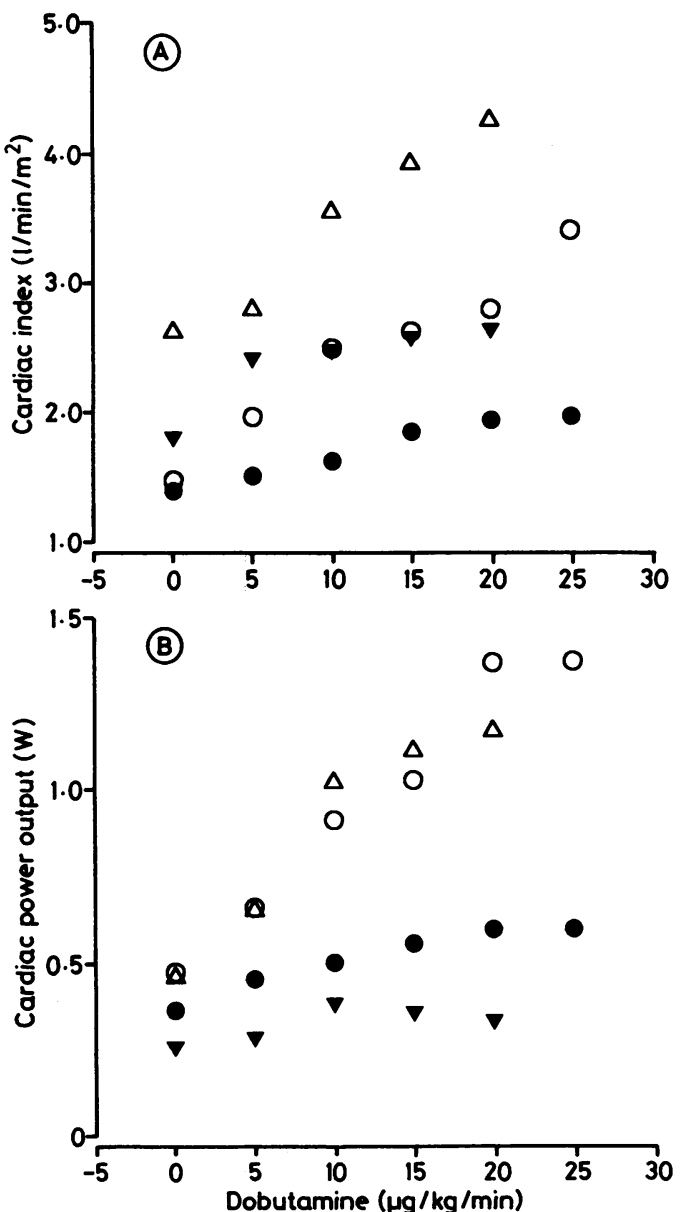

Figure 3 Responses to incremental dobutamine infusion in terms of $(A)$ cardiac index and $(B)$ cardiac power output. Each symbol represents the responses of an individual patient (open symbols for survivors and filled symbols for non-survivors). 

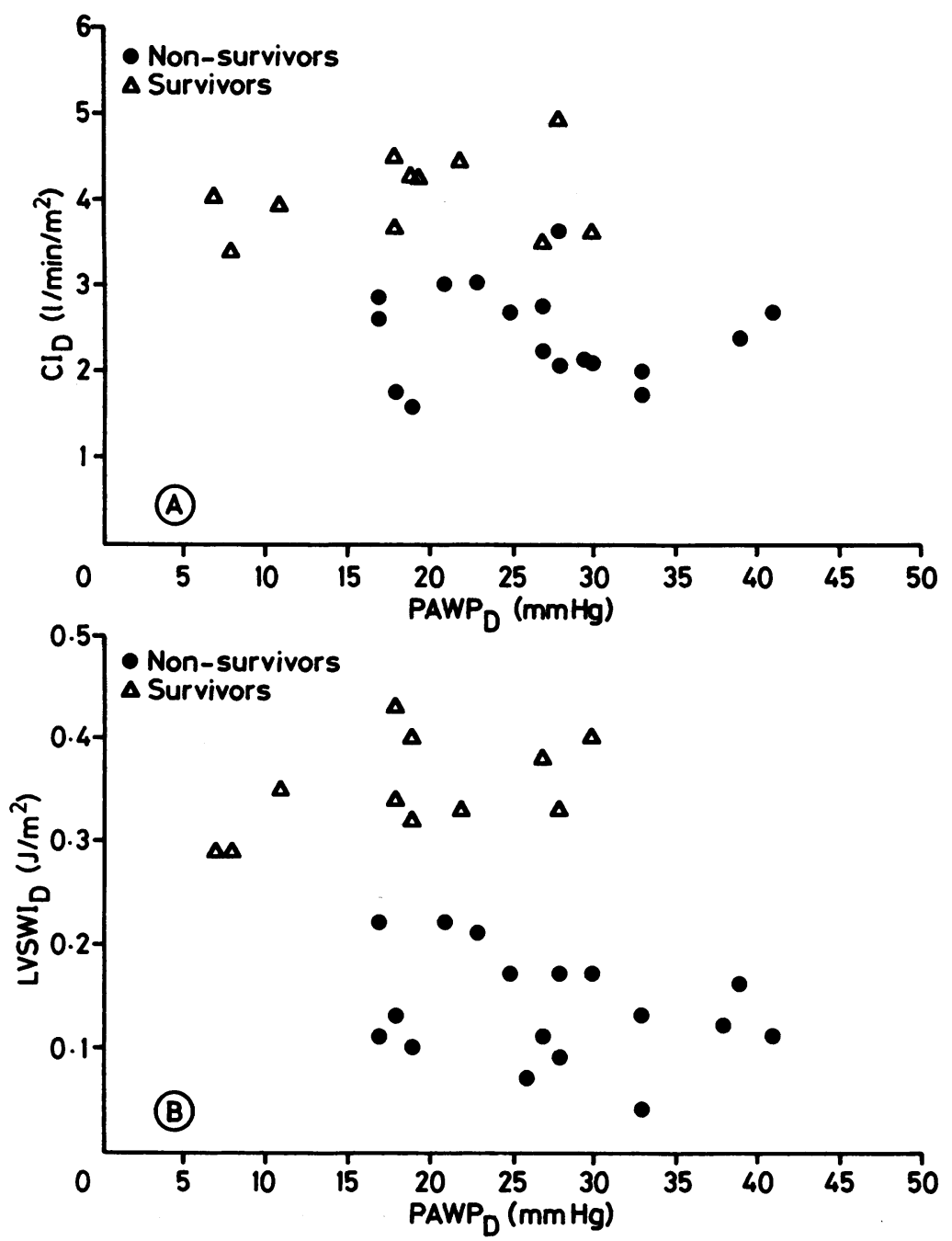

Figure 4 Relation between $(A)$ cardiac index and mean pulmonary artery wedge pressure ( $P A W P)$ and $(B)$ left ventricular stroke work index (LVSWI) and pulmonary artery wedge pressure during maximal dobutamine infusion.

in infusion rate tended not to produce concomitant increases in cardiac power output (fig 3B) but the cardiac output continued to increase (fig 3A).

Figure $3 \mathrm{~A}$ shows that the cardiac index doseresponse curves of the two patients (represented by open circles and filled inverted triangles) were similar. However, the cardiac power output dose-responses of the same two patients

\footnotetext{
Figure 5 Cardiac power output in basal resting state and during maximal dobutamine stimulation of individual patients (mean and $99 \%$ confidence intervals). The cardiac performance of patients with basal cardiac power outputs above $0.35 \mathrm{~W}$ (dotted line) is indistinguishable withou dobutamine stimulation. This became distinctly different during maximal dobutamine stimulation, with the survivors showing greater cardiac reserve, reaching peak power output of $>1 W$ (dashed line).
}

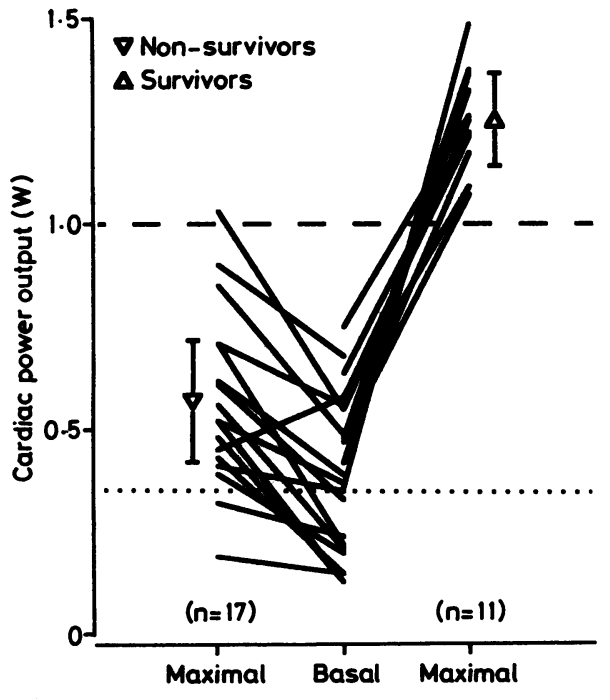

(fig 3B) were quite different. The patient who died reached a substantially lower peak cardiac power output.

The maximum dose of dobutamine used to determine cardiac reserve in the non-survivor group (25.6 (2.3) $\mu \mathrm{g} / \mathrm{kg} / \mathrm{min}$ ) was significantly higher $(p<0.05)$ than that used in the survivor group $(18 \cdot 2 \quad(1 \cdot 1) \mu \mathrm{g} / \mathrm{kg} / \mathrm{min})$. Survivors achieved maximal power output at lower rates of dobutamine infusion.

\section{HAEMODYNAMIC STATE AT MAXIMAL INOTROPIC} STIMULATION

Table 2 shows that maximal dobutamine stimulation significantly increased. the heart rate, mean arterial pressure, cardiac index, stroke volume index, stroke work index, and cardiac power output of the entire group and significantly decreased the right atrial pressure, pulmonary vascular resistance, and systemic vascular resistance. Pulmonary artery wedge and mean pulmonary arterial pressures did not change significantly in any group in response to dobutamine stimulation. The changes produced by dobutamine were not as statistically significant in the smaller subsets of survivors and non-survivors.

The measured haemodynamic data of survivors and non-survivors at basal resting state were not significantly different (table 2 ). At peak dobutamine stimulation, however, all variables indicative of systolic cardiac performance (cardiac index, stroke volume index, left ventricular stroke work index, and cardiac power output) in survivors were clearly different from those of non-survivors.

In contrast with figs $2 A$ and $B$, the relation between cardiac index and pulmonary artery wedge pressure and between left ventricular stroke work index and pulmonary artery wedge pressure during peak dobutamine infusion shown in figs $4 \mathrm{~A}$ and $\mathrm{B}$ were clearly able to identify the subset of non-survivors. Compared with the points in fig 2 the points in fig 4 were generally shifted to the left and upwards by the dobutamine challenge, but this shift was more noticeable in the survivors than in those who died.

\section{PEAK CARDIAC POWER OUTPUT AND PROGNOSIS}

Figure 5 shows the individual responses of cardiac power output to dobutamine stimulation. In patients with a basal resting cardiac power output of $\leqslant 0.35 \mathrm{~W}$ the outcome was uniformly death. Above this level, some had sufficient cardiac reserve to be able to respond to the dobutamine stimulation to produce peak cardiac power output of $>1 \mathrm{~W}$.These patients survived more than a year. The one exception (that is the patient with peak cardiac power output $>1 \mathrm{~W}$ who died) was the patient who was discharged home after acute myocardial infarction and was readmitted a month later and died of intractable ventricular tachycardia. Those who had limited cardiac reserve, such that the peak cardiac power output during maximal dobutamine challenge was $\leqslant 1 \mathrm{~W}$, died. Also the mean values of peak cardiac power output of survivors and non-survivors, together with the $99 \%$ confidence limits 
(shown as error bars in fig 5), were clearly separate.

\section{Discussion \\ COMPARISON OF BASAL AND PEAK STIMULATED CARDIAC PUMPING STATES}

Haemodynamic evaluation at basal resting state confidently predicted mortality in a group of patients in cardiogenic shock only when the cardiac pump failure was so severe such that resting cardiac index was $<1.31 . \mathrm{min}^{-1} . \mathrm{m}^{-1}$, left ventricular stroke work index was $<0.1 \mathrm{~J}^{-2}$ (fig 1), or cardiac power output was $<0.35 \mathrm{~W}$ (fig 5). At peak stimulation, however, haemodynamic assessment of the severity of cardiac dysfunction clearly identified which individual patient was going to die (figs 4 and 5).

One reason why the predictive value of resting basal cardiac performance is less is because the response to cardiac impairment in patients with cardiogenic shock is not uniform. Different combinations of compensatory neurohormonal responses are activated in different individuals-for example, some patients have a higher vagal tone while others have higher sympathetic tone. Another reason for the poorer predictive value of basal haemodynamic evaluation is that when the heart fails, the peak performance is compromised to a greater extent than the basal performance. ${ }^{12}$

Cardiac pumping capability assessed by pharmacological stimulation has been shown to correlate with that assessed by physiological stimulation via exercise testing. ${ }^{13}$ Thus cardiac reserve as estimated by dobutamine challenge can be taken to represent the functional capacity of the failing heart, and hence subsequent exercise capability ${ }^{12}$ and prognosis. ${ }^{9}$

\section{RESPONSE TO DOBUTAMINE CHALLENGE}

The dose-response curves for dobutamine (figs $3 A$ and $B$ ) highlight two related points. First, at the peak dosages further increases in infusion rate tended not to increase the cardiac power output (fig 3B) while the cardiac output continued to rise (fig 3A). The lack of increase in cardiac power output signified the cardiac pump's inability to respond to inotropic stimulation beyond a certain limit. The continued increase in cardiac output, on the other hand, was due to the systemic vasculature remaining responsive to further vasodilatory effects of dobutamine. Second, the relative positions of the four dose-response curves to dobutamine were dissimilar in the two figures (3A and 3B). The patients represented by filled inverse triangles and open circles in fig $3 \mathrm{~A}$ seemed to have similar cardiac index responses to dobutamine stimulation, but when the cardiac power output of these patients were plotted against the dobutamine dosage (fig 3B) the curves were quite different and were more predictive of the clinical outcome. For these reasons the maximal cardiac response to dobutamine stimulation was determined in our protocol by the peak cardiac power output and not peak cardiac output.

The cardiac index was significantly increased by maximal dobutamine stimulation of the heart (table 2). This increase was not only caused by the significant increase in heart rate but also by the significant increase in stroke volume, which was partly due to the vasodilatation caused by dobutamine, as shown by the decrease in systemic vascular resistance. Because the mean arterial pressure was significantly raised by dobutamine, however, and in the absence of any increase in preload (no rise in pulmonary artery wedge pressure), the increase in stroke volume must have also been the result of the positive inotropic response of the failing hearts to dobutamine. ${ }^{14}$ Hence, dobutamine challenge produced enhanced cardiac systolic performance by using the inotropic and chronotropic reserves. This led to significant increases in left ventricular stroke work index and cardiac power output. Also though the basal cardiac power output was marginally lower among those who died, the percentage increase was smaller in this group than among those who survived $(67.6 \%$ v $140.4 \%, \mathrm{p}<0.01$ ), indicating a considerable difference in cardiac reserve.

\section{PROGNOSTIC INDICATORS IN CARDIOGENIC \\ SHOCK}

Clinical evaluation during cardiogenic shock is imprecise and cannot be relied upon to establish the severity of cardiac dysfunction or prognosis. For example, when they were first diagnosed as being in cardiogenic shock the patients were clinically indistinguishable and were all judged to have grave prognosis by the attending physicians. Nevertheless, the use of clinical acumen to make the diagnosis of cardiogenic shock is invaluable. The detection of oliguria or hypotension by cuff manometry has often been the first feature to alert the clinician to the presence of shock. The finding of a higher intra-arterial pressure in the presence of other clinical features of shock does not preclude the diagnosis of shock, especially in previously hypertensive patients. ${ }^{1015} \mathrm{We}$ therefore thought that to study how this new method of haemodynamic evaluation correlated with prognosis, it was more appropriate to base the diagnosis on clinical criteria than on conventional haemodynamic criteria. This may partly account for the higher survival rate $(39 \%)$ seen in our study as compared with previous published figures of $0-27 \%,{ }^{1}$ though a figure of $38 \%$ was reported more recently. ${ }^{16}$

There were many studies of prognostic indicators in cardiogenic shock in the early 1970s The management of cardiogenic shock has evolved substantially over the years. With medical treatment all patients with a cardiac index $<2.31 . \mathrm{min}^{-1} \cdot \mathrm{m}^{-2}$ and pulmonary artery wedge pressure of $>15 \mathrm{~mm} \mathrm{Hg}$ died in a series reported in $1972,{ }^{7}$ whereas several such patients survived in our series (fig 2A). Similarly, $93 \%$ of patients with stroke work index $<0.25$ g.m.m ${ }^{-2}$ died in $1972,{ }^{17}$ but only $63 \%$ died in our series. Haemodynamic criteria for diagnosing cardiogenic shock based on evaluation of cardiac function at basal resting states are liable to be either too stringent, so that some true cases of cardiogenic shock are not included, or too lax so that those with 
reasonable prognosis are given unnecessary treatment.

The outcome of patients in cardiogenic shock may depend on the progression of the underlying disease as well as on cardiac pumping reserve; and further deterioration, such as caused by ischaemia/infarction, is likely to contribute significantly towards further setbacks and mortality. However, our results showed that cardiac reserve, estimated soon after the onset of cardiogenic shock, correlated closely with the outcome during the one year of follow up. This implies that progression of coronary artery disease, in this population group, affects medium term prognosis only slightly, if at all. Another recent study also showed that, in patients in cardiogenic shock, the death rate in the first year after hospital discharge was low (only $4 \%,<1 / 10$ of inhospital mortality). ${ }^{18} \mathrm{~A}$ possible explanation of this is that by the time the patient reached the state of shock the damage to the jeopardised myocardium was probably complete, and, if not, then the shock state itself would ensure that any threatened myocardium was progressively infarcted. ${ }^{1920}$ This does not, however, preclude the possibility that further infarction and rhythm disturbances affect mortality in the longer term.

Figures 4A and $B$ show that the response to peak dobutamine stimulation distinguished the survivors from those who died. As pointed out above, a variable representing both the pressure and flow generating capacity of the failing heart, such as left ventricular stroke work index, gave a better separation of the data points of survivors from the non-survivors (fig 4B) than one measuring flow alone (fig 4A). The cardiac index-pulmonary wedge pressure criteria for identifying the groups with a poor prognosis, obtained during maximal dobutamine challenge, can now be defined as a cardiac index of $<3.1 \quad 1 . \mathrm{min}^{-1} \cdot \mathrm{m}^{-2}$ and pulmonary artery wedge pressure of $>17 \mathrm{~mm} \mathrm{Hg}$ (fig 4A); the left ventricular stroke work index-pulmonary wedge pressure criteria are a stroke work index of $<0.25 \mathrm{~J} / \mathrm{m}^{2}$ and a pulmonary artery wedge pressure of $>17 \mathrm{~mm} \mathrm{Hg}$ (fig 4B).

PEAK CARDIAC POWER OUTPUT AND PROGNOSIS Although the separation of the survivors from the non-survivors in fig $4 \mathrm{~B}$ is apparent, it does not explain why the survivors managed to do well despite the fact that the left ventricular stroke work index at peak dobutamine stimulation (mean of $0.35 \mathrm{~J} / \mathrm{m}^{-2}$, see table 2) was still significantly below the stroke work index of a healthy comparison group at rest without stimulation (mean of $0.52 \mathrm{~J} / \mathrm{m}^{2}$ ). ${ }^{21}$ One explanation is that the term, peak stroke work index, contains two of the three major components of cardiac reserve-that is, preload and contractility, leaving out heart rate. In the face of impaired contractility and maximal use of preload, the heart is highly dependent on its chronotropic competence to maintain adequate circulation. ${ }^{22}$

The inclusion of heart rate in stroke work leads to the term cardiac power output, which has been previously described as the entity solely responsible for the maintenance of the circulation. ${ }^{9}$ Survival was limited when the peak cardiac power output during maximal stimulation fell short of the normal value of the basal unstimulated state. ${ }^{9}$ Ideally, the normal basal cardiac power output of the individual patient should be compared with the value before the development of heart disease; but this is seldom known. The basal resting cardiac power output of an adult of average size (approximately $1 \mathrm{~W}$ ) was used instead.9 The results of this study (fig 5) accord with the supposition that if the function of the failing heart performing at its maximal capacity (peak cardiac power output) does not exceed that which is normally required during inactivity (cardiac power output of approximately $1 \mathrm{~W}$ ) then such a heart cannot be expected to sustain life for long. Conversely, when peak cardiac power output exceeds the normal basal cardiac power output, then, despite the peak left ventricular stroke work index being significantly below the normal basal stroke work index, the function of the failing heart would still be compatible with sustained survival.

\section{IMPLICATIONS FOR MANAGEMENT AND FUTURE RESEARCH}

Our results showed that patients with adequate cardiac reserve who were treated medically survived for more than a year. Should such patients have acute interventions, such as the insertion of ventricular assist devices, emergency coronary angioplasty, or coronary bypass surgery ? $^{23}$ These interventions are not without morbidity and mortality ${ }^{24}$ and their long term benefits are uncertain. A recent report suggests that coronary angioplasty improves the survival of patients in cardiogenic shock after infarction. ${ }^{26}$ However, the study had the shortcoming of being a retrospective unrandomised study with permissive criteria for patient selection (shock precipitated by drugs, arrhythmia, or heart block was not expressly excluded). Survival at $\mathbf{3 0}$ days was $50 \%$ in the angioplasty group and $17 \%$ in the medically treated group, but the angioplasty group was recruited between 1983 and 1985 and the medically treated group between 1975 and 1985. Our patients with cardiogenic shock were treated conservatively and in the same study period as the angioplasty group; their $\mathbf{3 0}$ day survival was $46 \%$. Prospective randomised trials in carefully selected patients are needed to establish the cost/benefit ratio of immediate and invasive interventions.

Randomisation of cardiogenic shock patients to evaluate the merits of different treatments has been regarded as ethically unacceptable. ${ }^{27}$ But randomisation of an objectively selected group of patients in cardiogenic shock who all have a grave prognosis is justifiable. It would also obviate such questions as whether intraaortic balloon counterpulsation should be started before or after a trial of maximal medical treatment (different institutions have different policies-for example, Pasternak and Braunwald's group recommends intra-aortic balloon counterpulsation when medical treatment fails, ${ }^{28}$ whereas Gunnar's group recommends 
intra-aortic balloon counterpulsation immediately. ${ }^{29}$ From our results, it is clear that the group with a poor prognosis should have intra-aortic balloon counterpulsation, whereas the group with a good prognosis should first be given inotropic support. This decision can be made early after the onset of cardiogenic shock, and does not have to wait until the patient becomes unresponsive to medical treatment. ${ }^{27}$ Future efforts should thus concentrate on the group with poor prognosis defined above. Those in whom surgery is clearly indicated should receive intervention at the appropriate time. Some patients may have a stunned myocardium $^{3031}$ and it is unclear whether inotropic support and the use of ventricular assist devices for a prolonged period would allow the stunned myocardium to recover sufficiently to avoid the need for cardiac transplantation. On the other hand, those patients in cardiogenic shock whose condition is identified to be truly terminal, and who (for whatever reasons) are not candidates for surgery, should not be put through frantic therapeutic manoeuvres that may postpone death but in so doing prolong suffering. ${ }^{32}$

\section{PRACTICAL GUIDELINES}

Our method can be simplified for use at the bedside. Once relative hypovolaemia and rhythm and conduction disturbances have been corrected in a patient in cardiogenic shock a basal cardiac index of $<1.31 . \mathrm{min}^{-1} \cdot \mathrm{m}^{-2}$, left ventricular stroke work index of $<0.1 \mathrm{~J} . \mathrm{m}^{-2}$, or cardiac power output of $<0.35 \mathrm{~W}$ identifies those with a grave prognosis. The dobutamine challenge test should be used in patients with higher values than these to see whether the maximal cardiac power output is $\angle 1.0 \mathrm{~W}$ and left ventricular stroke work index is $<0.25$ $\mathrm{J} / \mathrm{m}^{2}$; this too indicates a poor prognosis. In patients with a poor prognosis, medical treatment would be futile, and unless contraindicated, the patient will need intra-aortic balloon counterpulsation or other ventricular assist devices to sustain them until coronary recanalisation or transplantation.

We thank Mrs Elsie Gale and her team of technicians for their dedicated assistance and Mr David Ward for performing the statistical analysis.

This study was supported by the British Heart Foundation.

1 Ayres SM. The prevention and treatment of shock in acute myocardial infarction. Chest 1988;93(suppl):17S-21S.

2 Wanzer SH, Federman DD, Adelstein SJ, et al. The physician's responsibility toward hopelessly ill patients: a physician's responsibility toward hopelessly

3 Hill JD, Farrar DJ, Hershon JJ, et al. Use of prosthetic ventricle as a bridge to cardiac transplantation for postinfarction cardiogenic shock. $N$ Engl J Med 1986;314: infarction.

4 Farrar DJ, Hill JD, Gray LA, et al. Heterotopic prosthetic ventricles as a bridge to cardiac transplantation. A multicenter stud 3330 .
5 Mulcahy D, Wright C, Mockus L, Yacoub M, Fox K. Cardiac transplantation in severely ill patients requiring intensive support in hospital. BMJ 1988;296:817-9.

6 Resnekov L. Cardiogenic shock. Chest 1983;6:893-8.

7 Ratshin RA, Rackley CE, Russell RO. Hemodynamic evaluation of left ventricular function in shock complicating myocardial infarction. Circulation 1972;45:127-39.

8 Russell RO Jr, Rackley CE, Pombo J, Hunt D, Potanin C, Dodge HT. Effects of left ventricular filling pressure with acute myocardial infarction. J Clin Invest 1970;49: 1539-50.

9 Tan LB. Cardiac pumping capability and prognosis in heart failure. Lancet 1986;ii: 1360-3.

10 Cohn JN. Recognition and management of shock and acute pump failure. In: Hurst JW, ed. The heart. 5 th ed. New York: McGraw-Hill, 1982:463-76.

11 Vincent J-L, Weil MH, Puri V, Carlson RW. Circulatory shock associated with purulent peritonitis. Am J Surg 1981;142:262-70.

12 Tan LB. Clinical and research implications of new concepts in the assessment of cardiac pumping performance in heart in the assessment of cardiac pumping per

13 Tan LB, Bain RJI, Littler WA. Assessing cardiac pumping capability by exercise testing and inotropic stimulation. $B$ Heart $J$ 1989;62:20-5.

14 Tan LB, Murray RG, Littler WA. An analytical method to separate inotropic and vasodilatory drug effects in man. Cardiovasc Res 1987;21:625-30.

15 Strobeck JE. Cardiogenic shock. Heart Failure 1985; 13-35.

16 Vincent J-L, Carlier E, Berre J, et al. Administration of enoximone in cardiogenic shock. Am J Cardiol 1988;62: 419-23.

17 Prakash R, Forrester J, Parmley WW, Swan HJC. Prognostic implications of left ventricular stroke work index (SWI) in acute myocardial infarction [Abstract]. Clin Res 1972;20:391.

18 Stack RS, Califf RM, Hinohara T, et al. Survival and cardiac event rates in the first year after emergency coronary event rates in the first year after emergency coronary angioplasty for acute m

19 Hands ME, Rutherford JD, Muller JE, et al. The in-hospita development of cardiogenic shock after myocardial infarction: incidence, predictors of occurrence, outcome and prognostic factors. J Am Coll Cardiol 1989;14:40-6.

20 Gutovitz AL, Sobel BE, Roberts R. Progressive nature of myocardial injury in selected patients with cardiogenic shock. Am J Cardiol 1978;41:469-75.

21 Grossman W. Evaluation of systolic and diastolic function of the myocardium. In: Grossman W, ed. Cardiac catheterization and angiography, 3rd ed. Philadelphia: Lea and Febiger, 1986:301-19.

22 Colucci WS, Ribeiro JP, Rocco MB, et al. Impaired chronotropic response to exercise in patients with conges tive heart failure. Role of postsynaptic $\beta$-adrenergic detive heart failure. Role of postsynaptic $\beta$
sensitization. Circulation 1989;80:314-23.

23 Mathey D, Kuck KH, Remmecke J, Tilsner V, Bleifeld W. Transluminal recanalization of coronary artery thrombosis: a preliminary report of its application in cardiogen shock. Eur Heart J 1980;1:207-12.

24 Isner JM, Cohen SR, Virmani R, Lawrinson W, Roberts WC. Complications of the intra-aortic balloon counter pulsation device: clinical and morphologic observations in 45 necropsy patients. Am J Cardiol 1980;45:260-8.

25 McCabe JC, Abel RM, Subramaniam VA, Gay WA J Complications of intra-aortic balloon insertion and counterpulsation. Circulation 1978;57:769-73.

26 Lee L, Bates ER, Pitt B, Walton JA, Laufer N, O'Neill WW. Percutaneous transluminal coronary angioplasty improves survival in acute myocardial infarction complicated by cardiogenic shock. Circulation 1988;78:1345-51.

27 Moulopoulos S, Stamatelopoulos S, Petrou P. Intra-aortic balloon assistance in intractable cardiogenic shock. Eur Heart $J$ 1986;7:396-403.

28 Pasternak RC, Braunwald E, Sobel BE. Acute myocardia infarction. In: Braunwald E, ed. Heart disease. Philadelphia: WB Saunders, 1988:1279-1313.

29 Gunnar RM, Loeb HS. Shock in acute myocardial infarc tion: evolution of physiologic therapy. J Am Coll Cardio 1983;1:154-63.

30 Braunwald E, Kloner RA. The stunned myocardium: prolonged postischemic ventricular dysfunction. Circulation 1982;66:1146-9.

31 Ballantyne CM, Verani MS, Short HD, Hyatt G, Noon GP. Delayed recovery of severely "stunned" myocardium with the support of a left ventricular assist device after coronary the support of a left ventricular assist device after coronary

32 Ruark JE, Raffin TA, and the Stanford University Medica Center Committee on Ethics. Initiating and withdrawing life support. Principles and practice in adult medicine. $N$ life support. Principles and pra 